\title{
Defective yeast opsonisation of serum in sarcoidosis
}

\author{
N McI JOHNSON, M W McNICOL, A KAPOOR, J E BURTON-KEE AND \\ J F MOWBRAY
}

From the Willesden Chest Clinic, and the Department of Experimental Pathology, St Mary's Hospital Medical School, London

ABSTRACT We have studied the opsonising ability of the sera of 49 patients with sarcoidosis. The serum of $11(22 \%)$ patients was defective in this ability, whereas only two (4\%) of 46 clinic control ${ }_{i}^{+}$ subjects and three $(7 \%)$ of 43 laboratory control subjects showed this defect. The difference between $\mathbb{N}_{N}^{\circ}$ the prevalence of the defect in sarcoidosis and the control groups was statistically significant $(\mathrm{p}<0.01)$.윽 Although the patients with sarcoidosis who had this defect tended to have pulmonary infiltration, $\rightarrow$ this relationship was not statistically significant. Similarly, there was no correlation between the $\rightarrow$ activity of sarcoidosis and this defect, although there was a significant $(p<0.05)$ relationship between the opsonising defect and the persistence of circulating immune complexes. Serum opsonisation is a $\vec{\oplus}$ genetically linked host defence mechanism. Our findings suggest that the presence of this serum? defect may render a person more susceptible to sarcoidosis.

Approximately $5 \%$ of sera from a normal population fail to opsonise yeast for phagocytosis by normal human polymorphonuclear leucocytes. This defect is common and is thought to underlie much frequent infection and allergy in childhood. ${ }^{1}$ The process of opsonisation is an important part of the effector arm of host defence mechanisms. We have examined the sera of patients with sarcoidosis for the presence of this defect, because in this granulomatous disease it is presumed that the persistence of antigen or immune complexes may lead to chronic disease, and opsonisation is an important host defence mechanism that might prevent it.

\section{Patients}

Forty-nine patients with sarcoidosis were studied (31 men, 18 women). These were the first 49 to be seen at Willesden Chest Clinic or Central Middlesex Hospital during the period of this study. The mean age was 40 years (range 17-63 years), racial distribution was West Indian 28 $(57 \%)$, white $16(33 \%)$, and Indian five $(10 \%)$. Length of history ranged from less than one month to over 20 years (mean 4.9 years). A

Address for reprint requests: Dr N McI Johnson, Medical Unit, Middlesex Hospital, Mortimer Street, London W1. diagnosis of sarcoidosis was made on clinical $\stackrel{\circ}{\stackrel{\Phi}{\varrho}}$ features, chest radiography, and histology. Other $\overrightarrow{\vec{F}}$ causes for non-caseating granulomata were ex- $\bar{\exists}$ cluded as far as possible. An assessment of whether the disease was active or not was madeo at the time of the patients' visit on the basis of clinical, biochemical, or radiological features. Ato음 this visit a blood sample was taken for the measurement of opsonising activity, immune complexes, complement, and rheumatoid factor. At the end of the study the chest radiographsô taken on the day the blood samples were taken were assessed for the presence of음 lymphadenopathy, infiltration, or fibrosis without the observer having reference to the patients? names or clinical details. The standard stagingn of sarcoidosis was made: $0=$ normal chest ${ }^{\circ}$ radiograph; 1 = bilateral hilar lymphadenopathy only; 2 = bilateral hilar lymphadenopathy with pulmonary infiltration; $3=$ pulmonary infiltration or fibrosis alone.

Twenty-two male and 24 female control subjects were tested, the mean age was 31 years (range $14-?$ 74 years). The racial distribution was West Indian $11(24 \%)$, white seven (15\%), and Indian $28 \stackrel{+}{\circ}$ (61\%). These were healthy adults asked to attend Willesden Chest Clinic as recent im- $\stackrel{\mathbb{Q}}{\varrho}$ migrants to Brent or as contacts of patients witho tuberculosis. Forty-three normal laboratory and $\varnothing$ medical staff were also tested. 


\section{Laboratory methods}

Sera were separated within four hours of collection and stored at $-70^{\circ} \mathrm{C}$ until analysed.

The opsonisation test used was a slight modification of that described by Levinsky et al. ${ }^{2}$ Ten $\mu l$ of yeast particles and $10 \mu l$ of normal human polymorphonuclear leucocytes with a ratio of yeast to polymorphs of $5: 1$ were mixed together with $5 \mu \mathrm{l}$ of test serum in a Luckham plastic tube and the reaction mixture was made into a total volume of $200 \mu \mathrm{l}$, with barbitone buffer ( $\mathrm{pH} \mathrm{7.6)}$ with calcium (10 mM), and magnesium $(10 \mathrm{mM})$. The mixture was incubated at $37^{\circ} \mathrm{C}$ for 30 minutes on a rotating mixer. Control samples of $10 \mu \mathrm{l}$ yeast particles were made up to the same reaction volume and also incubated. Known samples of normal and defective serum samples were also included in each bath. After incubation the reaction mixture was diluted 1:500 with an automatic dilutor (Compupet, Warner Diagnostic). The red cells were lysed by the addition of a drop of Zaponin (Coulter Electronics, Harpenden) to each assay tube and the number of unphagocytosed yeast particles were counted in a Coulter counter. The results were expressed as percentage uptake of yeast particles by the normal polymorphs.

$$
\begin{aligned}
& \% \text { uptake }=\frac{t-y}{t} \times 100 \\
& t=\text { total number of yeast particles } \\
& y=\text { number unphagocytosed }
\end{aligned}
$$

Immune complexes were precipitated with $2 \%$ polyethylene glycol and the $\mathrm{Clq}$ and immunoglobulin determined as described by Nydegger et al. ${ }^{3}$ CH50 was measured by a standard functional assay, using sensitised sheep red cells, and $\mathrm{C} 3$ by single radial immunodiffusion. The antisera were raised in rabbits by immunisation with purified components, and standardised by comparison with reference antisera.

IgG rheumatoid factor was assayed by a latex glohwlin reagent (RA-test latex-globulin-Hyland).

\section{Results}

The sera "rom $11(22 \%)$ of the 49 patients with sarcoidosis had defective opsonisation ability, whereas only two (4\%) sera out of 46 from healthy subjects showed this defect $(p<0.01$ Fisher's exact test).

The racial distribution of the defect in sarcoidosis was white five $(31 \%)$, West Indian five $(18 \%)$, and Indian one $(20 \%)$. Of control subjects with the defect one was white and the other Indian. Three (7\%) of the 43 normal laboratory staff showed the defect.

Results showing the prevalence of immune complexes and rheumatoid factors in these patients will be presented elsewhere. There was a significant relationship ( $p<0.05$ Fisher's exact test) between the presence of circulating immune complexes and the opsonising defect (table 1). Nine $(82 \%)$ of the 11 patients with sarcoidosis with the defect had evidence of circulating immune complexes, whereas only $19(50 \%)$ of the 38 patients without the defect had complexes (figure). Rheumatoid factor was present in 14 $(29 \%)$ of the 49 patients. Only four patients with

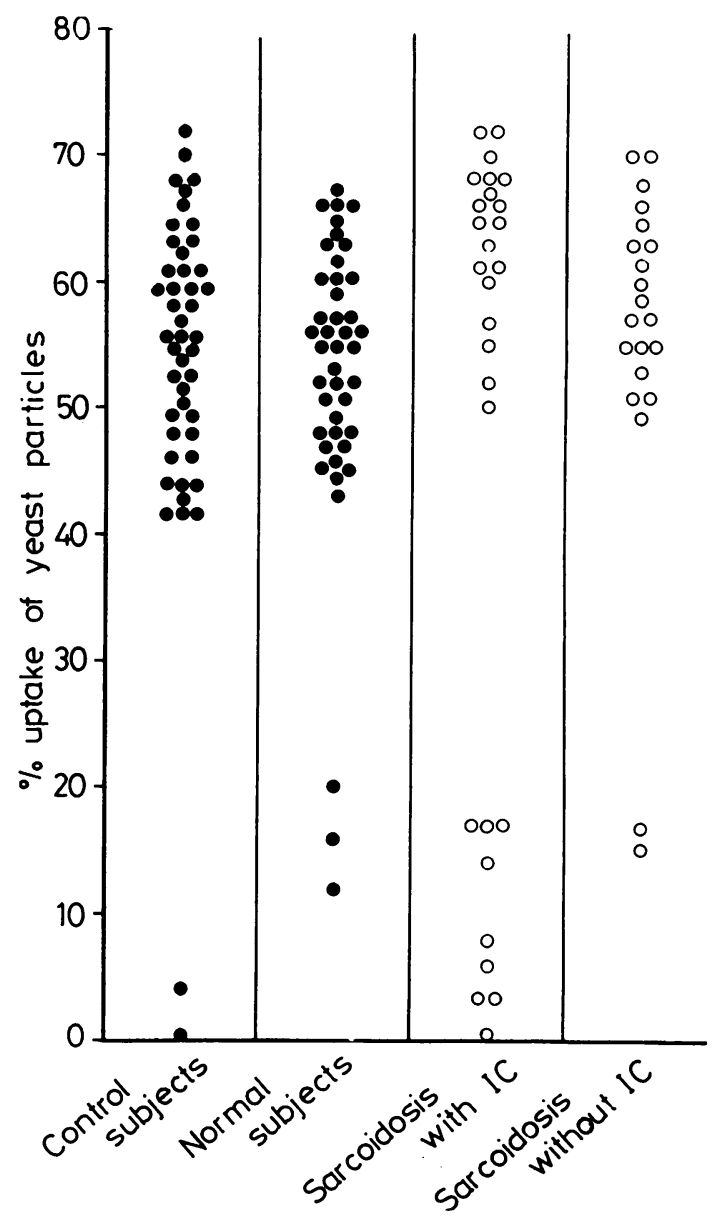

Figure Percentage opsonisation of yeast particles in control subjects, normal subjects, and patients with sarcoidosis with and without immune complexes (IC). 
Table 1 Opsonising defect and circulating immune complexes in sarcoidosis

\begin{tabular}{lcccc}
\hline Opsonisation & \multicolumn{3}{c}{ Immune complexes } \\
\cline { 2 - 5 } & + & - & Total \\
\hline Defective & $9 *$ & 2 & 11 \\
Normal & 19 & 19 & 38 \\
Total & 28 & 21 & 49 \\
\hline
\end{tabular}

*Significant difference $\mathrm{p}<0.05$ (Fisher's exact test)

the defect had rheumatoid factor, thus showing no correlation between the defect and its presence.

There was no correlation between the presence of the opsonising defect and the activity of sarcoidosis. The disease was judged to be active in nine $(82 \%)$ patients with the defect and 30 $(61 \%)$ without the defect.

Table 2 Stage of sarcoidosis and opsonisation in 49 patients

\begin{tabular}{llc}
\hline Stage & Defect & Normal \\
\hline 0 & 1 & 9 \\
1 & 2 & 11 \\
2 & 6 & 12 \\
3 & 2 & 6 \\
\hline
\end{tabular}

When stage of disease was considered (table 2) there was no definite pattern; however, of the patients with pulmonary infiltration or fibrosis (stages 2 and 3 ) eight out of $26(31 \%)$ had the defect, whereas only three out of $23(13 \%)$ of those without lung infiltration had the defect. This difference was not statistically significant $(p<0.09)$. Complement levels were normal (table 3).

Table 3 Complement levels

\begin{tabular}{lcccccc}
\hline Complement & \multicolumn{2}{l}{$\begin{array}{l}\text { Sarcoidosis patients } \\
(n=49)\end{array}$} & & \multicolumn{2}{c}{$\begin{array}{l}\text { Control subjects } \\
(n=46)\end{array}$} \\
\cline { 2 - 5 } & Mean* & $\pm S D$ & & & Mean* & $\pm S D$ \\
\hline C1q & 110 & 9 & 101 & 8 \\
CH50 & 99 & 9 & 106 & 7 \\
C3 & 101 & 11 & 102 & 9 \\
\hline
\end{tabular}

*Expressed as percentage of control pool of normal sera. Differences between normal and disease groups not significant.

\section{Discussion}

We have shown that $22 \%$ of sera from the patients with sarcoidosis and only $5 \%$ of the control sera had a defective opsonising ability, indicating a significant association between this defect and sarcoidosis. The prevalence of this defect in our control subjects is in agreement with that found in previous studies. ${ }^{12}$ We found $\overrightarrow{F_{n}}$ it impossible to obtain exact racial matching if our control group; however, the increasecf frequency of this defect was seen in each races tested and the increase was greatest in the whites $\mathbb{\mathrm { D }}$ Thus it is unlikely that lack of exact raciaf matching between our groups could account for the differences observed.

If the defect was caused by the disease, one might expect to find complement consumption ${ }_{\sigma}^{\omega}$ but the normal levels of complement do not support this. It is known that the opsonising defect is genetically controlled and may ber associated with gene products of the HLA region of the sixth chromosome. ${ }^{4}$ The molecular basio for the defect is unknown but can be restored by the addition of small amounts of normal plasma. ${ }^{15}$ Previous studies have shown this defect to be associated with frequent infection and allergy in childhood, and atopy presenting withinfantile eczema or hay fever. ${ }^{14}$

The patients with the defect tended to have pulmonary infiltration, although this difference was not statistically significant. The significance of our findings is uncertain. The increased frequency and the association of the defect witlo the persistence of circulating immune complexes suggests that it might have aetiological signifi $\vec{\not}$ cance by impairing antigen and immune complex 3 elimination, thereby leading to occurrence and persistence of the disease.

Further studies are necessary not only to find whether there is an increase in the incidence of sarcoidosis in patients with defective opsonisa-x tion but also to see whether patients with sarcoidosis and the defect develop progressive disease. At present the association we have found between sarcoidosis and the opsonising? defect does not appear to be of prognostis significance.

\section{References}

1 Soothill JF, Harvey BAM. Defective opsonisa tion. A common immunity deficiency Arch DiN

2 Lhild 1976; 51:91-9. objective method for measuring the yeas opsonisation activity of serum. J Immunol Methods 1978; 24:251-6.

3 Nydegger UE, Lambert PE, Gerber H, Miesche PA. Circulating immune complexes in the serumb in systemic lupus erythrematosus and in carriers? of hepatitis B antigen. Quantitation by binding to radio labelled Clq. J Clin Invest 1974; 54므 297-309.

4 Turner MW, Mowbray JF, Harvey 
Brostoff J, Wells RS, Soothill JF. Defective yeast opsonisation and $\mathrm{C} 2$ deficiency in atopic patients. Clin Exper Immunol 1978; 34:253-9.
5 Miller ME, Seals J, Haye R, Levitsky LC. A familial plasma-associated defect of phagocytosis. Lancet 1968; 2:60-3. 